\title{
Influência do substrato e do tamanho da célula de bandejas de poliestireno expandido no desenvolvimento de mudas e produção de calêndula (Calendula officinalis $L$.)
}

\author{
BARBOSA, C.K.R. ${ }^{1 *}$; VALADARES, S.V.'; BONFIM, F.P.G. ${ }^{2}$; HONORIO, I.C.G. ${ }^{1}$; MARTINS, E.R. ${ }^{1}$ \\ ${ }^{1}$ Instituto de Ciências Agrárias da Universidade Federal de Minas Gerais. Av. Universitária, 1000, Bairro Universitário, \\ CEP: 39.404-006, Montes Claros-Brasil *camilakarenr@gmail.com ${ }^{2}$ Departamento de Fitotecnia da Universidade \\ Federal de Viçosa. Av. PH Rolfs s/n - Campus Universitário, CEP: 36.570-000, Viçosa-Brasil
}

\begin{abstract}
RESUMO: A calêndula (Calendula officinalis L.) é uma planta medicinal anual de origem Mediterrânica que apresenta propriedades antiinflamatórias, antivirais, antigenotóxicas. A propagação desta planta normalmente é feita por sementes, sendo o uso de bandejas de poliestireno uma forma econômica de produção de mudas. Foram conduzidos dois experimentos com o objetivo de avaliar a interferência de dois tamanhos de célula em bandeja de poliestireno expandido $\left(40 \mathrm{~cm}^{3}\right.$ e $\left.12 \mathrm{~cm}^{3}\right)$ e de dois substratos (solo + esterco bovino curtido e substrato comercial tipo Plantmax para hortaliças ${ }^{\circledR}$ ) sobre a qualidade de mudas e a produção de calêndula. O delineamento estatístico nos dois experimentos foi em blocos casualizados, dispostos em arranjo fatorial $2 \times 2$ (dois substratos e dois tamanhos de células) com seis repetições. Os tratamentos, referentes aos tamanhos das células foram bandeja com 128 células $\left(40 \mathrm{~cm}^{3} \mathrm{de}\right.$ volume) e, bandeja com 288 células ( $12 \mathrm{~cm}^{3}$ de volume). Os substratos utilizados foram solo de cerrado + esterco bovino curtido (1:1) e substrato comercial tipo "Plantmax para hortaliças ${ }^{\circledR "}$. Parte das mudas foi transplantada para avaliação da produção de capítulos. Houve diferenças significativas entre os substratos para as variáveis: matéria seca de parte aérea, matéria seca da raiz e matéria seca total. $\mathrm{O}$ uso do substrato formulado com solo de cerrado e esterco bovino proporcionou o melhor desenvolvimento das mudas de calêndula. Contudo, os diferentes tipos de substrato e bandejas de poliestireno não influenciaram significativamente a produção de capítulos das mudas transplantadas.
\end{abstract}

Palavras-chave: plantas medicinais, cultivo orgânico, produção de mudas, calêndula

\begin{abstract}
Influence of substrate and cell size of expanded polystyrene tray on the development and production of marigold (Calendula officinalis L.) seedlings. Marigold (Calendula officinalis L.) is an annual medicinal plant of Mediterranean origin which presents antiinflammatory, antiviral and antigenotoxic properties. This species normally propagates through seeds, and the use of polystyrene trays is an economic way to produce its seedlings. Two experiments were carried out to evaluate the influence of two cell sizes of expanded polystyrene trays $\left(40 \mathrm{~cm}^{3}\right.$ and $12 \mathrm{~cm}^{3}$ ) and two substrates (soil + cattle manure and Plantmax ${ }^{\otimes}$ commercial substrate for vegetables) on marigold production and seedling quality. Experimental design in both assays was in randomized blocks, in a $2 \times 2$ factorial arrangement (two substrates and two cell sizes), with six replicates. Treatments regarding cell sizes were trays presenting 128 cells $\left(40 \mathrm{~cm}^{3}\right)$ and trays containing 288 cells $\left(12 \mathrm{~cm}^{3}\right)$. The used substrates were cerrado soil + cattle manure $(1: 1)$ and Plantmax ${ }^{\circledR}$ commercial substrate for vegetables. Part of the seedlings was transplanted to evaluate capitulum production. There were significant differences among substrates for total, root and shoot dry matter. The use of substrate containing cerrado soil and cattle manure led to the best development of marigold seedlings. However, the different types of substrates and polystyrene trays did not significantly influence capitulum production in transplanted seedlings.
\end{abstract}

Key words: medicinal plants, organic cultivation, seedling production, marigold

Recebido para publicação em 07/10/2008

Aceito para publicação em 22/09/2009

Rev. Bras. PI. Med., Botucatu, v.12, n.1, p.18-22, 2010. 


\section{INTRODUÇÃO}

No Brasil, as plantas medicinais assumem papel importante no desenvolvimento da sociedade, sendo que as deficiências do sistema de saúde pública e a baixa renda da maioria da população fazem com que grande parte utilize as plantas medicinais como recurso terapêutico (Scheffer et al., 1999).

Segundo Oliveira et al. (2006), os trabalhos desenvolvidos em comunidades, Organizações não governamentais (ONGs) e Instituições públicas (municipais, estaduais e federais) fortalecem as iniciativas que utilizam esta prática no atendimento da população. Muitos médicos da Rede Pública de Saúde (SUS), mesmo sem o incentivo desejado do governo municipal, prescrevem fitoterápicos, os quais fazem parte de sua prática médica. Segundo este mesmo autor, a calêndula (Calendula officinallis) está entre as três plantas mais utilizadas na cidade de São Paulo.

A calêndula, planta medicinal anual de origem Mediterrânica, tem como principal efeito terapêutico a cicatrização de tecido cutâneo, tratamento de abscessos gástricos e inflamações utilizando o extrato alcoólico das inflorescências, além disso, é utilizada externamente contra conjuntivites, herpes e gengivites (Lorenzi \& Matos, 2002). Muito cultivada no sul do país para fins ornamentais e para apoio à indústria de cosméticos, a espécie multiplica-se por sementes. O uso de bandejas de isopor na produção de mudas tem se mostrado eficiente sob diversos aspectos, pois, além de poderem ser reutilizadas, apresentam vantagens como economia de substrato e espaço. Dessa forma, a semeadura indireta para a produção de mudas e posterior transplantio constitui o método de propagação mais empregado (Oliveira et al., 1993; Figueira, 2000).

Na produção de mudas de boa qualidade, o tamanho do recipiente e o tipo do substrato são os primeiros aspectos a serem investigados (Marques et al., 2003). O primeiro afeta diretamente o volume disponível para o desenvolvimento das raízes e o segundo garante bom estado nutricional das plantas, afetando a qualidade das mudas (Carneiro, 1983).

O substrato para a produção de mudas deve garantir o desenvolvimento de uma planta com qualidade e uniforme em curto período de tempo e baixo custo. A qualidade física do substrato é importante, por ser utilizado num estádio de desenvolvimento em que a planta é muito suscetível ao ataque por microrganismos e pouco tolerante ao déficit hídrico (Cunha et al., 2006). Dessa forma, o substrato deve reunir características físicas e químicas que promovam o desenvolvimento das mudas com potencial máximo.

O objetivo deste trabalho foi avaliar a interferência do tamanho das células da bandeja de isopor e de dois substratos sobre a qualidade de mudas e a produção de capítulos florais de calêndula.

\section{MATERIAL E MÉTODO}

O experimento foi realizado em condições de casa de vegetação, no Instituto de Ciências Agrárias da Universidade Federal de Minas Gerais, Campus Montes Claros - MG.

Experimento 1: Qualidade das mudas de calêndula

O delineamento estatístico utilizado foi inteiramente casualizado (DIC), em esquema fatorial 2x2 (dois tamanhos de células em bandeja de isopor e dois substratos), com seis repetições, sendo cada unidade experimental constituída de 40 células da bandeja de isopor com uma planta cada.

Os tratamentos referentes aos tamanhos das células foram: bandeja com 128 células $\left(40 \mathrm{~cm}^{3}\right.$ por célula) e, bandeja com 288 células ( $12 \mathrm{~cm}^{3}$ por célula). Os substratos utilizados foram: 1) solo de cerrado + esterco bovino curtido - 1:1 - v/v - e, 2) substrato comercial tipo "Plantmax para hortaliças ${ }^{\circledR}$ ".

As características do substrato comercial utilizado (Tabela 1) podem ser encontradas no site do fabricante. A análise química do substrato comercial realizada por Danner et al. (2007) e do solo de cerrado utilizado são apresentados na Tabela 2.

TABELA 1. Características do substrato comercial Plantmax para hortaliças ${ }^{\circledR}$ fornecida no site da empresa fabricante.

\begin{tabular}{lc}
\hline Umidade $(\%)$ & até 50 \\
\hline Capacidade de retenção de água $(\%)$ & 150 (mínimo) \\
\hline Potencial hidrogeniônico - pH & $5,8( \pm 0,5)$ \\
\hline Condutividade elétrica - CE $\left(\mathrm{mS} \mathrm{cm}^{-1}\right)$ & $1,3( \pm 0,3)$ \\
\hline
\end{tabular}

Fonte:http://www.eucatex.com.br/eucatex/descricao. asp? $A 1=14 \& A 2=71$

A semeadura foi realizada a $1,0 \mathrm{~cm}$ de profundidade com a distribuição de três sementes da variedade comercial "Bonina Dobrada Sortida" por célula da bandeja. Dez dias após foi realizado o desbaste, deixando-se uma planta por célula.

As mudas foram mantidas em bandejas, em casa de vegetação, por 30 dias, quando 0 desenvolvimento foi avaliado. Para tanto, foram levadas ao Laboratório de Plantas Medicinais e lavadas em água corrente, sendo retirado o substrato aderido às raízes. Seccionou-se a região do colo das plantas e o material foi levado à estufa de secagem com circulação forçada de ar, a $60^{\circ} \mathrm{C}$, até atingir massa constante. Determinou-se a matéria seca da parte aérea (MSPA), a matéria seca das raízes (MSR) e matéria seca total (MST), além da relação raiz/parte aérea (RELRPA). A RELRPA foi determinada pela divisão de MSR por MSPA. Os resultados foram submetidos à análise de variância. 
TABELA 2. Análise do solo de cerrado utilizado para o cultivo de calêndula em Montes Claros, MG, realizada no Laboratório de Solos do Instituto de Ciências Agrárias da Universidade Federal de Minas Gerais.

\begin{tabular}{lrr}
\hline & \multicolumn{2}{c}{ Solo } \\
\cline { 2 - 3 } Atributos do solo & Cerrado & Comercial \\
\hline $\mathrm{pH}$ em água & 1,8 & 5,1 \\
P-Mehlich 1 $\left(\mathrm{mg} \mathrm{dm}^{-3}\right)$ & 37,5 & 311,3 \\
P- remanescente $\left(\mathrm{mg} \mathrm{L}^{-1}\right)$ & 14 & 762,45 \\
$\mathrm{~K}\left(\mathrm{mg} \mathrm{dm}^{-3}\right)$ & 0,3 & 14,94 \\
$\mathrm{Ca}\left(\mathrm{cmol}_{\mathrm{c}} \mathrm{dm}^{-3}\right)$ & 0,2 & 12,14 \\
$\mathrm{Mg}\left(\mathrm{cmol}_{\mathrm{c}} \mathrm{dm}^{-3}\right)$ & 0,5 & 0,1 \\
$\mathrm{Al}\left(\mathrm{cmol}_{\mathrm{c}} \mathrm{dm}^{-3}\right)$ & 2,9 & 6,53 \\
$\mathrm{H}+\mathrm{Al}\left(\mathrm{cmol}_{\mathrm{c}} \mathrm{dm}^{-3}\right)$ & 0,54 & 29,03 \\
$\mathrm{SB}\left(\mathrm{cmol}_{\mathrm{c}} \mathrm{dm}^{-3}\right)$ & 1,04 & 35,56 \\
$\mathrm{t}\left(\mathrm{cmol}_{\mathrm{c}} \mathrm{dm}^{-3}\right)$ & 48 & 0,31 \\
$\mathrm{~m}(\%)$ & 3,43 & - \\
$\mathrm{T}\left(\mathrm{cmol}_{\mathrm{c}} \mathrm{dm}^{-3}\right)$ & 16 & 81,64 \\
V $(\%)$ & 2 & 13 \\
Mat. Orgânica $\left(\mathrm{dag} \mathrm{Kg}^{-1}\right)$ & 22 & - \\
Areia grossa $\left(\mathrm{dag} \mathrm{Kg}^{-1}\right)$ & 60 & - \\
Areia fina $\left(\mathrm{dag} \mathrm{Kg}^{-1}\right)$ & 4 & - \\
Silte $\left(\mathrm{dag} \mathrm{Kg}^{-1}\right)$ & 14 & - \\
Argila $\left(\mathrm{dag} \mathrm{Kg}^{-1}\right)$ & &
\end{tabular}

Experimento 2: Produção de capítulos $O$ delineamento estatístico foi inteiramente casualizado (DIC), disposto em fatorial $2 \times 2$, com seis repetições, sendo cada unidade experimental constituída de vasos de $4 \mathrm{dm}^{3}$ com duas plantas cada e preenchidos com solo de cerrado e esterco bovino curtido na proporção 1:1 (v/v) e mantidos em casa de vegetação. Os tratamentos foram as mudas provenientes de dois tamanhos de célula de bandeja (40 e $12 \mathrm{~cm}^{3}$ de volume) e dois substratos (solo de cerrado + esterco bovino curtido - 1:1 - v/v - e, comercial do tipo "Plantmax para hortaliças ${ }^{\circledR}$ ").

As mudas transplantadas, com idade de 30 dias, iniciaram a produção de capítulos cerca de 20 dias após o transplantio e permaneceram em casa de vegetação até completarem o ciclo de produção floral de 30 dias. Nesse período, foi realizada a colheita e a determinação do número de capítulos florais produzidos (NC) e da matéria seca comercial dos capítulos (MSC), após secagem em estufa com circulação forçada de ar a $40^{\circ} \mathrm{C}$ para obtenção do material seco comercial. Os resultados foram submetidos à análise de variância.

\section{RESULTADO E DISCUSSÃO} calêndula

Experimento 1: Qualidade das mudas de

Não foram observadas interações significativas entre o tipo de bandeja e os substratos, somente $o$ efeito isolado desses fatores em algumas das variáveis (Tabela 3 ). Tal resultado é semelhante ao observado por Nicoloso et al. (2000), que submeteram a espinheira-santa (Maytenus ilicifolia Martius ex Reissek) e grápia [Apuleia leiocarpa (Vogel) Macbride] a diferentes recipientes e substratos na produção de mudas.

Foram observadas diferenças significativas entre os substratos. O substrato formulado apresentou as maiores médias para MSPA, MSR e MST (Tabela 3), semelhante ao observado por Farinacio \& Godoy (2007) na produção de mudas de alface, onde os substratos alternativos proporciononaram grande potencial de produção das mudas. Os resultados indicam o uso do substrato formulado com solo e esterco bovino para produção de mudas com melhor desenvolvimento. Quanto ao tipo de bandeja, o volume das células não influenciou significativamente a qualidade das mudas (Tabela 4), podendo-se optar por bandeja com maior número de células, maximizando a produção de mudas em menor espaço e com economia de substrato. Este resultado diferiu daqueles observados por Modolo \& Tessarioli Neto (1999), Resende et al. (2003) e Seabra Júnior et al. (2004), que avaliaram o desenvolvimento e a produtividade de quiabo, alface americana e pepino, respectivamente, sendo que o tamanho das células da bandeja interferiu significativamente nas variáveis analisadas. Esta variável está relacionada ao volume de substrato disponível para desenvolvimento das raízes (Carneiro,1983). Assim, o volume da menor célula não limita o desenvolvimento radicular das mudas de calêndula até os 30 dias, quando devem ser transplantadas, maximizando a utilização de espaço, com economia de substrato.

\section{Experimento 2: Produção de capítulos}

Quanto à produção de capítulos, não foram observadas diferenças significativas para NC e MSC (Tabela 5) evidenciando que o tipo de bandeja e substrato não interfere na produção de capítulos após o transplantio, embora haja interferência no desenvolvimento das mudas. Resultado semelhante ao encontrado por Mota et al. (2007), ao avaliarem a 
floração de calêndula produzida em diferentes níveis de adubação química fosfatada e, distinto ao encontrado por Marques et al. (2003), ao verificarem que a produção de mudas de alface em bandejas com diferentes números de células interferiu no desenvolvimento da muda à campo, onde a célula de menor volume de substrato produziu mudas inferiores e pior desempenho da produção de campo.

As bandejas com 288 células ( $12 \mathrm{~cm}^{3}$ célula-1), por permitirem maior produção por área, são mais apropriadas para a formação de mudas de Calendula officinalis $\mathrm{L}$.

O uso do substrato formulado com solo de cerrado e esterco bovino proporcionou o melhor desenvolvimento das mudas de calêndula, entretanto, pode-se optar pelo substrato comercial, uma vez que as mudas de melhor desenvolvimento se equivalem àquelas menos desenvolvidas após o transplantio, resultando em plantas com produção similar de capítulos.

TABELA 3. Valores médios para as variáveis matéria seca da parte aérea (MSPA), matéria seca da raiz (MSR), matéria seca total (MST), relação da raiz com parte aérea (RELRPA) de calêndula produzida em diferentes tipos de substratos, em Montes Claros - MG.

\begin{tabular}{cccccc}
\hline Tratamentos & MSPA (g) & MSR (g) & MST (g) & RELRPA (g) \\
\hline $\begin{array}{c}\text { Substrato formulado } \\
\text { (solo + esterco bovino) }\end{array}$ & 0,0407 a & 0,0285 a & 0,0692 a & 1,4022 a \\
Substrato comercial & $0.0196 \mathbf{b}$ & 0,0159 b & 0,0355 b & 1,2500 a \\
\hline
\end{tabular}

As médias seguidas da mesma letra minúscula, na coluna, não diferem estatisticamente entre si pelo teste $\mathrm{F}$ a $5 \%$ de probabilidade.

TABELA 4. Valores médios para as variáveis matéria seca da parte aérea (MSPA), matéria seca da raiz (MSR), matéria seca total (MST), relação da raiz com parte aérea (RELRPA) de calêndula produzida em diferentes tipos de bandejas de poliestireno, em Montes Claros - MG.

\begin{tabular}{ccccc}
\hline Tratamentos & MSPA (g) & MSR (g) & MST (g) & RELRPA (g) \\
\hline $\begin{array}{c}\text { Bandeja - 128 células } \\
\left(40 \mathrm{~cm}^{3} \text { de volume }\right)\end{array}$ & 0,0322 a & 0,0238 a & 0,0560 a & 1,3139 a \\
$\begin{array}{c}\text { Bandeja - 288 células } \\
\left(12 \mathrm{~cm}^{3} \text { de volume }\right)\end{array}$ & 0,0282 a & 0,0207 a & 0,0488 a & 1,3382 a
\end{tabular}

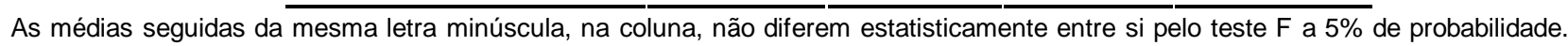

TABELA 5. Análise de variância para as variáveis número de capítulos (NC) e matéria seca de capítulos (MSC) de calêndula produzida em diferentes tipos de substratos e bandejas de poliestireno, em Montes Claros - MG.

\begin{tabular}{crrr}
\hline \multirow{2}{*}{ Fontes de Variação } & \multirow{2}{*}{ G.L. } & \multicolumn{2}{c}{ Quadrados médios } \\
\cline { 2 - 4 } & & \multicolumn{1}{c}{ NC } & \multicolumn{1}{c}{ MSC } \\
\hline Tamanho da célula & 1 & 0,010362 & 0,00085 \\
Sustrato & 1 & 0,00002960 & 0,000067 \\
Substrato x célula & 1 & 0,00902 & 0,0016 \\
Resíduo & 20 & 0,012278 & 0,001294 \\
Total & 23 & & \\
\hline C.V. $(\%)$ & \multicolumn{3}{r}{25,826} \\
\hline
\end{tabular}

*- Significativo a $5 \%$ de probabilidade pelo teste $\mathrm{F}$. 


\section{REFERÊNCIA}

CARNEIRO, J.G.A. Variações na metodologia de mudas florestais afetam os parâmetros morfo-fisiológicos que indicam a sua qualidade. Série Técnica FUPEP, v.12, p.1-40, 1983.

CUNHA, A.M. et al. Efeito de diferentes substratos sobre o desenvolvimento de mudas de Acacia sp. Revista Árvore, v.30, p.207-14, 2006.

DANNER, M.A. et al. Formação de mudas de jabuticabeira (Plinia sp.) em diferentes substratos e tamanhos de recipientes. Revista Brasileira de Fruticultura, v.29, n.1, p.179-82, 2007.

FARINACIO, D.; GODOY, W.I. Avaliação de substratos alternativos para a produção de mudas de alface em bandeja. In: SEMINÁRIO DE INICIAÇÃO CIENTÍFICA E TECNOLÓGICA DA UTFPR, 12., Curitiba. Anais ... Curitiba: Editora UTFPR, 2007. p.39-42.

FIGUEIRA, F.A.R. Novo manual de olericultura: agrotecnologia moderna na produção e comercialização de hortaliças. Viçosa: Universidade Federal de Viçosa, 2000. 402p.

LORENZI, H.; MATOS, F.J.A. Plantas medicinais no Brasil: nativas e exóticas. Nova Odessa: Plantarum, 2002. 512p.

MARQUES, P.A.A. et al. Qualidade de mudas de alface formadas em bandejas de isopor com diferentes números de células. Horticultura Brasileira, v.21, n.4, p.649-51, 2003.

MODOLO, V.A.; TESSARIOLI NETO, J. Desenvolvimento de mudas de quiabeiro [Abelmoschus esculentus (L.)
Moench] em diferentes tipos de bandeja e substrato. Scientia Agrícola, v.56, n.2, p.377-81,1999.

MOTA, J.H. et al. Produção de calêndula sob diferentes níveis de fósforo. In: CONGRESSO BRASILEIRO DE OLERICULTURA, 47., 2007, Porto Seguro. Horticultura Brasileira, v.25, n.1, 2007. CD ROM.

NICOLOSO, F.T. et al. Recipientes e substratos na produção de mudas de Maytenus ilicifolia e Apuleia leiocarpa. Ciência Rural, v.30, n.6, p.995-1000, 2000. OLIVEIRA, M.J.R.; SIMOES, M.J.S.; SASSI, C.R.R. Fitoterapia no Sistema de Saúde Pública (SUS) no Estado de São Paulo, Brasil. Revista Brasileira de Plantas Medicinais, v.8, n.2, p.39-41, 2006.

OLIVEIRA, R.P.; SCIVITTARO, W.B.; VASCONCELLOS, L.A.B.C. Avaliação de mudas de maracujazeiro em função do substrato e do tipo de bandeja. Scientia Agricola, v.50, n.2, p.261-6, 1993.

RESENDE, G.M. de et al. Efeitos de tipos de bandejas e idade de transplantio de mudas sobre o desenvolvimento e produtividade da alface americana. Horticultura Brasileira, v.21, n.3, p.558-63, 2003.

SCHEFFER, M.C.; ARAUJO, A.J.; MING, L.C. Conservação de recursos genéticos de plantas medicinais. In: QUEIROZ, M.A. Recursos genéticos e melhoramento de plantas para o Nordeste brasileiro. Petrolina: Embrapa/Cenargen, 1999. v.1, p.1-25.

SEABRA JUNIOR, S.; GADUM, J.; CARDOSO, A.I.I. Produção de pepino em função da idade das mudas produzidas em recipientes com diferentes volumes de substrato. Horticultura Brasileira, v.22, n.3, p.610-3, 2004. 